\title{
Lactose intolerance at a day care center in the municipality of Duque de Caxias, Rio de Janeiro, Brasil
}

\author{
Isaac Azevedo Tenorio*, Aderbal Sabra, Selma Sabra \\ From 3rd WAO International Scientific Conference (WISC) 2014 \\ Rio de Janeiro, Brazil. 6-9 December 2014
}

\section{Objectives and study}

Lactose intolerance has a variable prevalence in different parts of the world. The differences may be explained by the diverse eating habits of each population, allowing over the years a selection of individuals with and without the ability to digest lactose - ontogenetic variation. The objective of this study is to identify the prevalence of lactose intolerance and their presenting main symptoms, developed by children at a Day care center in the municipality of Duque de Caxias, Rio de Janeiro, Brazil, after an oral lactose tolerance test.

\section{Methods}

Oral lactose tolerance test was done in all children at the daycare center. At the end of the test a questionnaire was held to identify symptoms. A hundred children were analyzed (61\% male and $39 \%$ female), between 2 and 13 years (30\% from 2 to 4 years; $37 \%$ from 5 to 7 years; $24 \%$ from 8 to 10 years; and $9 \%$ from 11 to 13 years).

\section{Results}

The blood test showed $52 \%$ of the children with positive results for lactose intolerance and $48 \%$ were negative. From the questionaires answers were gotten in $64 \%$ of the patients. Lactose intolerance (positive test with symptoms) was present in $20.3 \%$ of the samples. Inconclusive results (positive test without symptoms and negative test with symptoms) reached $42.2 \%$ of the samples. Healthy patients represent $37.5 \%$ of the studied population. Among the symptoms, diarrhea was the most prevalent (50\%), followed by abdominal pain and headache $(20 \%)$, and flatus/abdominal distension (5\%).

\footnotetext{
Unigranrio, Brazil
} any medium, provided the original work is properly cited. The Creative Commons Public Domain Dedication waiver (http:// creativecommons.org/publicdomain/zero/1.0/) applies to the data made available in this article, unless otherwise stated. 